Article

\title{
Improving Air Quality in the Po Valley, Italy: Some Results by the LIFE-IP-PREPAIR Project
}

\author{
Katia Raffaelli ${ }^{1, *}$, Marco Deserti ${ }^{1}$, Michele Stortini ${ }^{2}$, Roberta Amorati ${ }^{2}$, Matteo Vasconi ${ }^{2}$ \\ and Giulia Giovannini ${ }^{2}$ \\ 1 Emilia-Romagna Region-Air and Water Protection and Restoration Service, 40127 Bologna, Italy; \\ marco.deserti@regione.emilia-romagna.it \\ 2 Regional Agency for Prevention, Environment and Energy of Emilia-Romagna (ARPAE), \\ 40126 Bologna, Italy; mstortini@arpae.it (M.S.); ramorati@arpae.it (R.A.); \\ mvasconi@arpae.it (M.V.); ggiovannini@arpae.it (G.G.) \\ * Correspondence: katia.raffaelli@regione.emilia-romagna.it; Tel.: +39-051-5276-988
}

Received: 28 February 2020; Accepted: 21 April 2020; Published: 23 April 2020

\begin{abstract}
The Po Valley (Northern Italy) represents an important exceedance zone of the air-quality limit values for $\mathrm{PM}$ (particulate matter), $\mathrm{NO}_{2}$ (nitrogen dioxide) and $\mathrm{O}_{3}$ (ozone). This area covers the territory of most Italian northern regions and includes several urban agglomerates, such as Milan, Turin, Venice and Bologna. The area is densely populated and heavily industrialized. The paper summarizes the assessment of the impact of the current (2013) and future (2025) emissions and of the meteorological conditions on the air quality of the Po Valley. This study is one of the first outcomes of the EU LIFE-IP Clean Air Program Po Regions Engaged to Policies of Air (PREPAIR) project. The project, involving administrations and environmental agencies of eight regions and three municipalities in Northern Italy and Slovenia, started in 2017 and will end in 2024. Future emission scenarios consider the emissions reduction due to the air-quality action plans of the regions involved, of the agreements between the national authorities and regional administrations and of the PREPAIR project itself, in the overall context of the application of the current legislation of the European Union. The combination of these measures will lead to the reduction of direct emissions of $\mathrm{PM}_{10}$ in the Po Valley and of the main precursors emitted in the area ( $\mathrm{NOx}$, nitrogen oxides and $\mathrm{NH}_{3}$, and ammonia) by $38 \%$ for $\mathrm{PM}_{10}, 39 \%$ for $\mathrm{NOx}$ and $22 \%$ for $\mathrm{NH}_{3}$, respectively. This lowering corresponds to a reduction of about 30.000 tons of primary $\mathrm{PM}_{10}, 150.000$ tons of $\mathrm{NOx}, 54.000$ tons of $\mathrm{NH}_{3}$ and 1700 tons of $\mathrm{SO}_{2}$. The results show that these expected reductions should allow us to achieve the EU $\mathrm{PM}_{10}$ limit value in the Po Valley by the year 2025.
\end{abstract}

Keywords: air-quality model; reduction emission scenario; air-quality action plan; Po Valley

\section{Introduction}

The Po Valley represents a non-attaining zone for PM (particulate matter), $\mathrm{NO}_{2}$ (nitrogen dioxide) and $\mathrm{O}_{3}$ (ozone), thus the need of enforcing the respect of the EU air quality limit values. This zone covers the territory of several regions in Northern Italy and includes many urban agglomerates, such as Milan, Turin, Venice and Bologna. The area is densely populated and heavily industrialized.

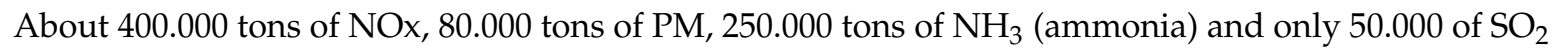
are emitted per year, into the atmosphere, by a wide variety of pollution sources, which are mainly related to traffic, domestic heating, industry and energy production, agriculture and farming activities.

Meteorological conditions and the resulting efficiency of the transport and dispersion of pollutants are strongly influenced by the morphological characteristics of the Po Valley and the Northern Adriatic Basin. The transport of pollutants, of the main drivers of ozone and of secondary particulate, are limited 
by the Alps, the Apennines and the Dinaric Alps. Due to both the dominating meteorological conditions and the morphologic characteristics of the Po valley, pollutants' background concentrations are often high, with a large part of the particulate matter being due to secondary production.

Although all the regions in the Po Valley have been implementing air-quality plans over the last decades, such plans turned out not to be fully effective in achieving a sufficient reduction of PM, $\mathrm{NO}_{2}$ and $\mathrm{O}_{3}$ concentration levels below the EU limit values. Previous experience demonstrates that coordinated and large-scale actions are necessary in this area. A comprehensive policy, acting on a large scale and on several sources of pollutant precursors of $\mathrm{PM}$ and $\mathrm{O}_{3}$, is essential in order to further reduce pollution levels. In order to reduce such levels of air pollution, all the regions have clustered in the so-called Po Basin Board and planned actions, with the aim of further reducing the emission of pollutants and their precursors. The need for implementing such coordinated actions led the National and Regional governments to sign a first agreement, in December 2013, aimed at developing and coordinating short- and long-term measures for improving the air quality of the Po Valley. This first Po Valley Agreement identifies the main sectors where actions are needed: biomass burning, transportation of goods and passengers, domestic heating, industry and energy, and agriculture. In 2017 a second Agreement was signed among the four Regions Emilia-Romagna, Lombardy, Piedmont and Veneto, for the implementation of further measures in the field of biomass burning, circulation of diesel vehicles and use of fertilizers in agriculture.

The aim of this work is to evaluate the effectiveness of the emission reduction measures achieved by a number of emission scenarios, in order to meet compliance with the limit values of $\mathrm{PM}_{10}$ and $\mathrm{NO}_{2}$ set up by the Air Quality Directive 2008/50/EC(AQD) [1].According to the AQD, The most critical air-quality standards in the Po Valley, according to the AQD, are considered in this work: the 24-hourlimit value of $\mathrm{PM}_{10}\left(50 \mu \mathrm{g} / \mathrm{m}^{3}\right.$ to not exceed for more than 35 days each year) and the annual mean limit value of $\mathrm{NO}_{2}\left(40 \mu \mathrm{g} / \mathrm{m}^{3}\right)$. The evaluation was achieved through the use of the air-quality models suite NINFA (Northern Italy Network to Forecast Aerosol pollution) [2,3]. NINFA is the operational Transport Model of the Environmental Agency of the Emilia-Romagna Region (ARPAE). The model suite includes a Chemical Transport Model (CTM), a meteorological model and an emissions preprocessing tool. The CTM is nested (one-way nesting) by taking initial and boundary conditions from a larger-scale model.

\section{LIFE Integrated Project (IP)Po Regions Engaged to Policies of Air (PREPAIR)}

The LIFE integrated project (IP)Po Regions Engaged to Policies of Air (PREPAIR) [4] supports the implementation of the regional air-quality plans (AQPs) and of the Po Valley agreements on a larger scale, acting in a synergic way, so to strengthen the sustainability and durability of the results. Although the geographical coverage of the project is the Po Valley and of the regions and urban areas that mainly influence air quality in the basin, the project actions are extended to Slovenia, in order to assess and reduce pollutants transport across the Adriatic Sea. Regarding air quality, in fact, all the regions located south of the Alps face the same adverse climatic conditions, which require higher technical and financial efforts, in comparison with other regions, to resolve compliance problems, as we try to show later.

The project PREPAIR, which started in 2017 and lasts until 2024, is financed under the EU LIFE Program for a total budget of $17 \mathrm{M} €$, in order to improve air quality in the Po Valley and in Slovenia and fully comply with the Directive 2008/50/EC and the European strategy for clean air, but it also contributes to the attempt to reach the objectives of the National Emission Ceilings Commitments and other environmental policies, like energy efficiency and climate action.

The main goal of PREPAIR is to increase the know-how of public bodies and private operators. Among all the measures foreseen in the regional AQPs, PREPAIR focuses, in particular, on four main sectors: biomass burning, energy efficiency, transport and agriculture. The project also aims at integrating a wide set of technical tools (emissions inventories, air-quality models, enhanced monitoring stations, etc.) that, up until now, have been implemented independently in the various 
regions. This goal will be achieved by establishing a permanent networking structure between the environmental agencies of the Po Valley and of Slovenia. During the first phase of the project, the impact on the air quality of the Po Valley of several groups of measures, related to different levels of government, was evaluated. The group of measures considered are as follows:

- The current legislation measures, which will be fully implemented by 2025 through the enforcement of the EU and member states' legislations;

- The national/interregional measures established by the agreements between the Regions of the Po Valley and the Italian government;

- The AQPs implemented by the regions.

\section{The Emission Scenarios in LIFE-IP PREPAIR}

\subsection{Baseline Scenario}

In the first phase of PREPAIR, a common emission inventory has been implemented in the project area. All available emission data for the Po Valley and Slovenia have been collected and analyzed [5]. Po Valley inventories were made using the INEMAR system [6] and following the national methodologies and the methodologies reported by the EMEP/EEA Atmospheric Emission Inventory Guidebook (AEIG) [7]

The dataset covers an area of about $135,000 \mathrm{~km}^{2}$ with a population of about 28 million people (Figure 1).

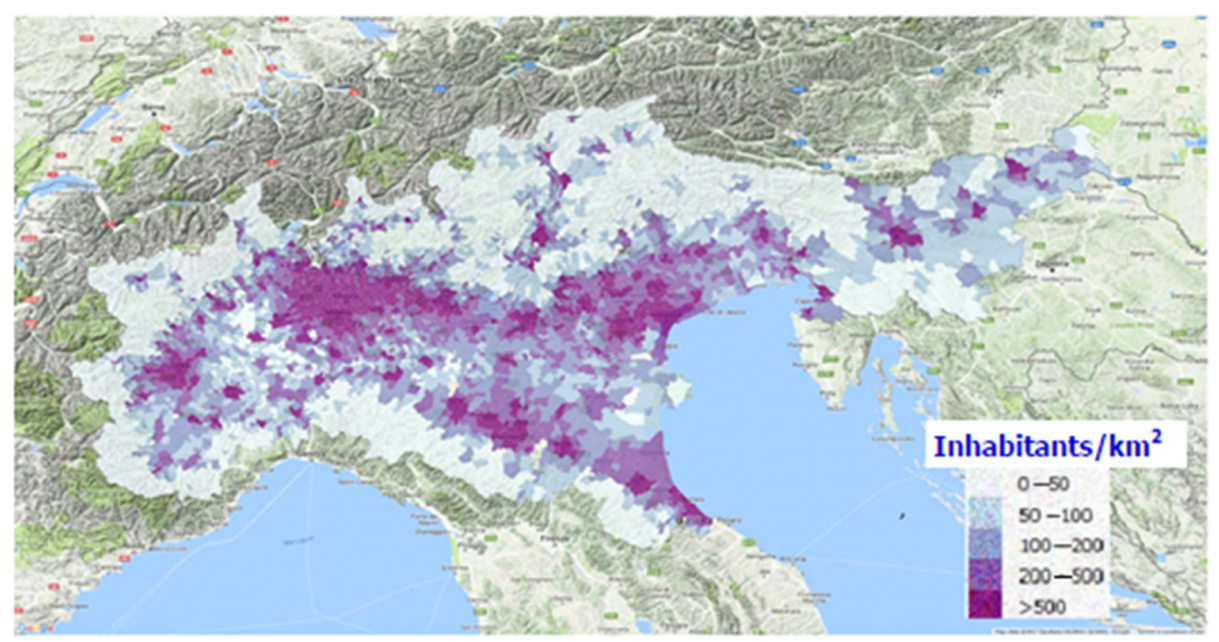

Figure 1. Po Regions Engaged to Policies of Air (PREPAIR)project target area.

The emission dataset refers to the year 2013 and contains the emissions for each municipality. It was obtained merging local and national inventories (in the case of Slovenia), maintaining the greatest possible detail. In this way, it is possible to identify extremely localized or peculiar sources of a specific area. In Table 1, the emissions of main pollutants related to the air pollution of the Po Valley are summarized. The Table shows that the major contributor to the production of primary $\mathrm{PM}_{10}$ is the sector non-industrial combustion plants, which mostly contributing through biomass burning. The second contributor is the sector road transport. As far as $\mathrm{NO}_{2}$ is concerned, the biggest contribution is due to road transport and secondarily to combustion in the manufactory industry. Considering ammonia, an important precursor of secondary particulate, it is evident that almost all the emissions are produced by agriculture, while organic compounds, contributing to the formation both of $\mathrm{PM}_{10}$ and ozone, are mainly emitted by the sector solvent and other products. As far as $\mathrm{SO}_{2}$ is concerned, the biggest contribution is due to combustion in the manufactory industry and secondarily to production processes. Because the domestic heating in the Po Valley mainly employs natural gas, the total amount of $\mathrm{SO}_{2}$ emissions is negligible in comparison with $\mathrm{NOx}(1 / 8)$ and $\mathrm{NH}_{3}(1 / 5)$. 
Table 1. Emissions for PoValley, baseline 2013.

\begin{tabular}{|c|c|c|c|c|c|c|}
\hline Macro-Sectors & $\mathrm{NH}_{3}$ & $\begin{array}{l}\text { Non-Methane Organic } \\
\text { Compound (NMVOC) }\end{array}$ & $\begin{array}{l}\text { NMVOC without } \\
\text { MS10 and MS11 }\end{array}$ & NOx & $\mathrm{PM}_{10}$ & $\mathrm{SO}_{2}$ \\
\hline $\begin{array}{l}\text { MS1-Combustion in energy and } \\
\text { transformation industries }\end{array}$ & $0 \%$ & $0 \%$ & $0 \%$ & $6 \%$ & $1 \%$ & $18 \%$ \\
\hline MS2-Non-industrial combustion plants & $0 \%$ & $5 \%$ & $11 \%$ & $9 \%$ & $56 \%$ & $7 \%$ \\
\hline MS3-Combustion in manufacturing industry & $0 \%$ & $1 \%$ & $2 \%$ & $15 \%$ & $4 \%$ & $41 \%$ \\
\hline MS4-Production processes & $0 \%$ & $4 \%$ & $9 \%$ & $3 \%$ & $3 \%$ & $21 \%$ \\
\hline $\begin{array}{l}\text { MS5-Extraction and distribution of fossil fuel } \\
\text { and geothermal energy }\end{array}$ & $0 \%$ & $2 \%$ & $4 \%$ & $0 \%$ & $0 \%$ & $0 \%$ \\
\hline MS6-Solvent and other product & $0 \%$ & $28 \%$ & $58 \%$ & $0 \%$ & $5 \%$ & $0 \%$ \\
\hline MS7-Road transport & $1 \%$ & $6 \%$ & $14 \%$ & $50 \%$ & $20 \%$ & $1 \%$ \\
\hline MS8-Other mobile sources and machinery & $0 \%$ & $1 \%$ & $2 \%$ & $13 \%$ & $4 \%$ & $10 \%$ \\
\hline MS9_-Waste treatment and disposal & $1 \%$ & $0 \%$ & $0 \%$ & $1 \%$ & $0 \%$ & $2 \%$ \\
\hline MS10-Agriculture & $97 \%$ & $22 \%$ & $0 \%$ & $1 \%$ & $4 \%$ & $0 \%$ \\
\hline M11-Other sources and sinks & $0 \%$ & $31 \%$ & $0 \%$ & $0 \%$ & $3 \%$ & $0 \%$ \\
\hline Total Emissions & $100 \%$ & $100 \%$ & $100 \%$ & $100 \%$ & $100 \%$ & $100 \%$ \\
\hline
\end{tabular}

\subsection{The Current Legislation Scenario}

The emissions scenario related to the implementation of the current legislation in the year 2025 is called CLE2025. The emission reduction for CLE2025 has been estimated by the application of emission projections provided, for each Italian region, by the Greenhouse Gas and Air Pollution Interactions and Synergies (GAINS)-Italian national model [8] managed by National Agency for new Technologies Energy and Sustainable Economic Development (ENEA). Starting from the baseline scenario, projections are calculated by a time proxy obtained from GAINS trends. The time projections are calculated for each sector and activity and remapped to Standard Nomenclature for Air Pollution (SNAP) and fuel categories. The methodology is described in detail in the PREPAIR report [5].

\subsection{The Action-Plans Scenario}

The action-plans scenario (hereafter scenario APS2025) is the emissions scenario which considers the emissions resulting from the reduction measures due to the full application of the combination of the current legislation plus the air-quality plans (AQPs), plus the Po Basin Agreement, plus the PREPAIR actions. The APS2025 scenario was built thanks to the web-based platform realized by PREPAIR. This platform, called "System for the environmental accountability of the measures of AQ plans", collects data about all the actions for the Po valley implemented by the regions and in the project itself. The data in the platform are constantly updated by the project partners. The system includes a web-based tool used by the project partners for periodically monitoring and updating the actions/measures. With this system, a common database has been produced which contains a catalogue of all the emissions reduction measures included in the AQPs and of the measures adopted by the regions, thanks to the Po Valley Agreements. The database considers both end-of-pipe (technological) and energy/behavior (non-technological) measures.

Among the non-technological measures, the improved performances of the emissions reduction of AQPs due to the PREPAIR project were also considered. The PREPAIR actions mainly consist of communication actions (workshops, guidelines, promotion, citizen's involvement, etc.) that act in four different sectors: agriculture, biomass burning, transports and energy efficiency. The different levels of expected improvement were estimated for the different types of action, considering the intensity of application and the numbers of activities involved.

Due to this "basin approach", the measures adopted by the regions in their own AQPs will lead to a comprehensive framework and strategy necessary to improve air quality in the whole area. Table 2, below, summarizes the 382 measures included in the Catalogue of Measures. 
Table 2. Catalogue of Measures, technological/non-technological measures.

\begin{tabular}{cccc}
\hline PREPAIR Sectors & Technological Measures & Non-Technological Measures & Total Measures \\
\hline Agriculture and livestock & 8 & 42 & 50 \\
\hline Green areas and forests & 0 & 2 & 2 \\
\hline Cross-sector actions & 2 & 58 & 60 \\
\hline Energy, networks and infrastructures & 6 & 18 & 24 \\
\hline Industry and productive activities & 12 & 19 & 31 \\
\hline Civil sector and public administration & 18 & 50 & 68 \\
\hline Transports and mobility & 23 & 124 & 147 \\
\hline Total number of measures & 69 & 313 & 382 \\
\hline
\end{tabular}

The emissions levels [9] related to the main pollutants ( $\mathrm{NOx}, \mathrm{PM}_{10}, \mathrm{NH}_{3}$ and $\mathrm{SO}_{2}$ ), for the three following scenarios, are shown in Figures 2-5:

- $\quad$ Baseline scenario (EMI2013);

- Current legislation scenario (CLE2025);

- Action-plans scenario (APS2025).

From the figures, the following can be seen:

In the CLE2025 scenario, most of emissions reductions are due to the traffic macro-sector: overall NOx decrease is about $30 \%$, while $\mathrm{PM}_{10}$ decrease is only $10 \%$. Ammonia $\left(\mathrm{NH}_{3}\right)$ emissions increase slightly (ammonia is an important PM precursor), and $\mathrm{SO}_{2}$ emissions do not change at all.

In the APS2025 scenario, the emission reductions are higher for all pollutants: NOx decrease is $39 \%, \mathrm{PM}_{10} 38 \%, \mathrm{PM}_{25} 40 \%, \mathrm{NH}_{3} 22 \%$ and $\mathrm{SO}_{2} 3 \%$. These high emissions decreases are due mainly to the reduction measures applied to agriculture (the main source of ammonia) and domestic biomass burning (the main source of primary $\mathrm{PM}_{10}$ ) sectors. Such sectors are regulated by the regions through the air-quality plans (AQPs) and the Rural Development Programs (RDP). Another relevant sector on which the air-quality plans acts mobility management. Measures such as the promotion of cycle-pedestrian mobility or the introduction of low-emission zones also contribute to reducing the emissions levels, as well as the effectiveness of European approval limits for vehicles.

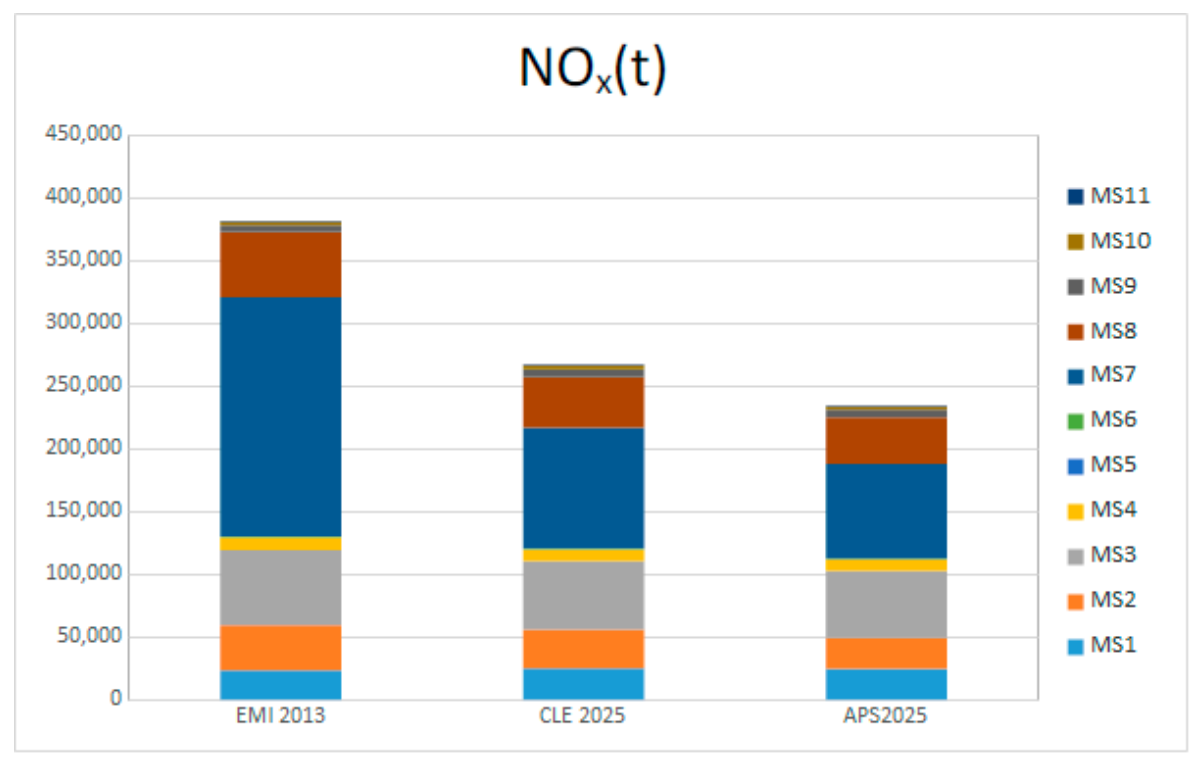

Figure 2. Emission scenarios for NOx. 


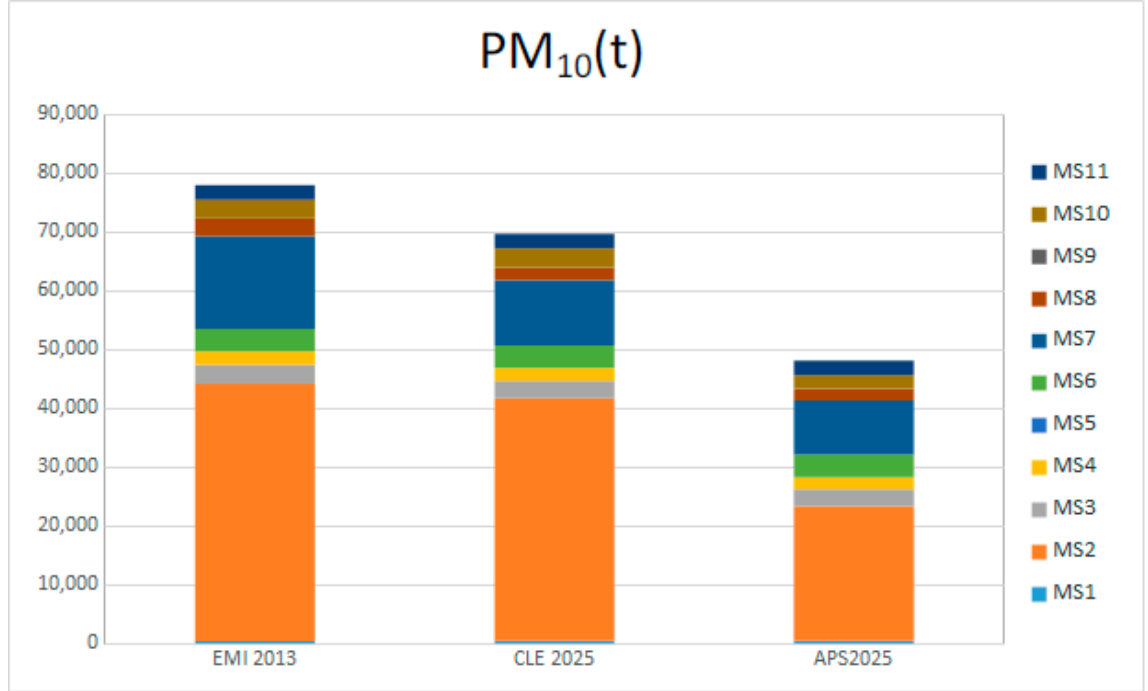

Figure 3. Emission scenarios for $\mathrm{PM}_{10}$.

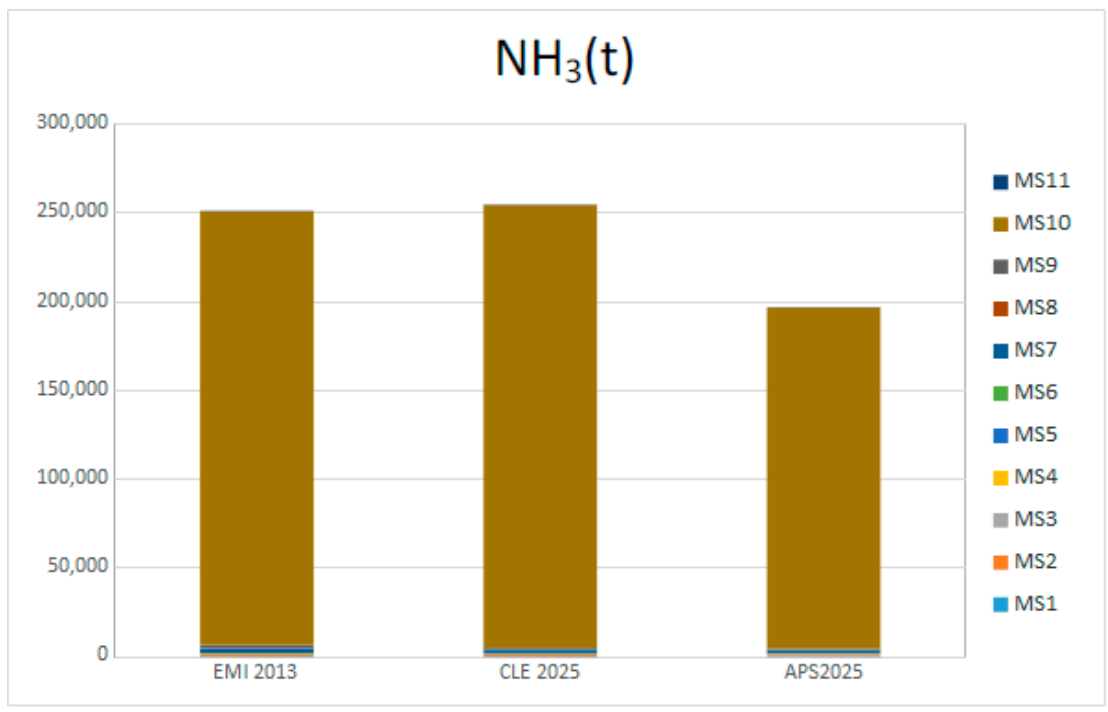

Figure 4. Emission scenarios for $\mathrm{NH}_{3}$.

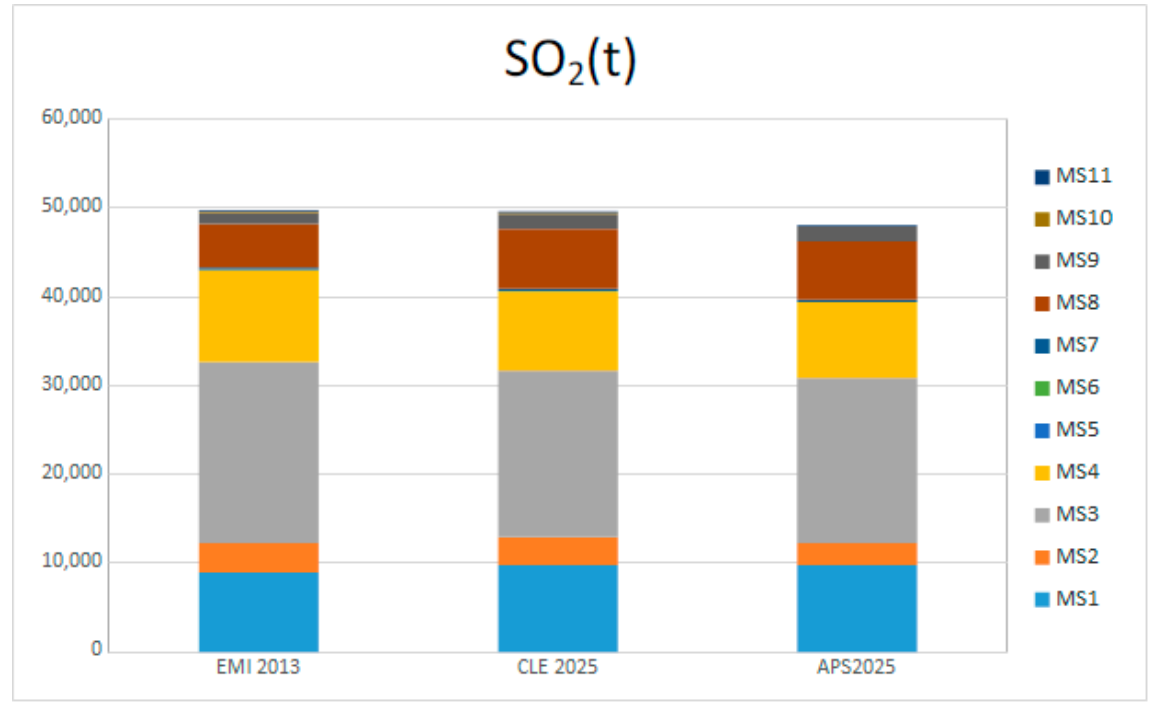

Figure 5. Emission scenarios for $\mathrm{SO}_{2}$. 


\section{Chemical Transport Model Simulation (CTM)}

\subsection{Definition of CTM Model Setup}

The pollutants concentration in air due to the emissions scenarios described above has been evaluated by using the air-quality-models suite NINFA (Northern Italy Network to Forecast Aerosol pollution [2,3]. NINFA is the operational AQ model of the Environmental Agency of the Emilia-Romagna Region (ARPAE). The model suite includes a Chemical Transport Model (hereafter CTM), a meteorological model and an emissions preprocessing tool. The CTM is nested (one-way nesting) by taking initial and boundary conditions from larger-scale national or continental models.

The chemical transport model is CHIMERE [10], an Eulerian-type numerical model, which simulates transport, dispersion, chemical transformations and deposition (dry and wet) of air pollutants and aerosols. The model input data are emissions, meteorology and physiographic data. The model includes routines that calculate biogenic, dust and sea salt additions that contribute to the anthropogenic emissions provided as input.

Starting from the emission data for the Po Valley, Slovenia and the other regions/countries present in the model domain, as described above, the emissions are prescribed to the numerical model by using specific proxy variables for each emission activity SNAP (i.e., road network for traffic emission, population and urban fabric for domestic heating, and so on).

The meteorological hourly input is provided by COSMO, the National NWP model used by the National Civil Protection Department [11,12]. COSMO is a non-hydrostatic, limited-area atmospheric prediction model, based on the primitive thermo-hydrodynamical equations describing compressible flow in a moist atmosphere, with a variety of physical processes taken into account by dry and moist parameterization schemes.

The time-dependent boundary conditions (with hourly frequency) can be provided either by PREV'AIR (the French national platform of quality air forecast covering Europe) [13], or by the Italian CAMS downstream service [14].

\subsection{The Model Runs}

For this work, NINFA is integrated at $0.07 \times 0.05$-degree horizontal resolution, nine vertical levels from surface up to $500 \mathrm{hPa}$, in hindcast mode for one year, using COSMO meteorology, with hourly boundary conditions coming from PREV'AIR.

The meteorological hourly input data are from the 1 January 2016 to 31 December 2016 period. Moreover, 2016 represents the median year in the time series of the number of days with meteorological conditions favorable to the $\mathrm{PM}_{10}$ accumulation in the Po Valley.

The model was run to evaluate the ground level pollutants concentrations for the three emission scenarios described in Section 3 and summarized here below:

1. Baseline emission scenario: emissions levels in the reference year 2013;

2. CLE2025 current legislation scenario;

3. APS2025 air-quality plans scenario: maximum feasible reduction due to current legislation plus the implementation of the AQPs, the Po valley agreement and the action of PREPAIR project in the year 2025 .

Figure 6 shows an example of the $\mathrm{NO}_{2}$ emission maps fed into the model for the three simulated scenarios. 


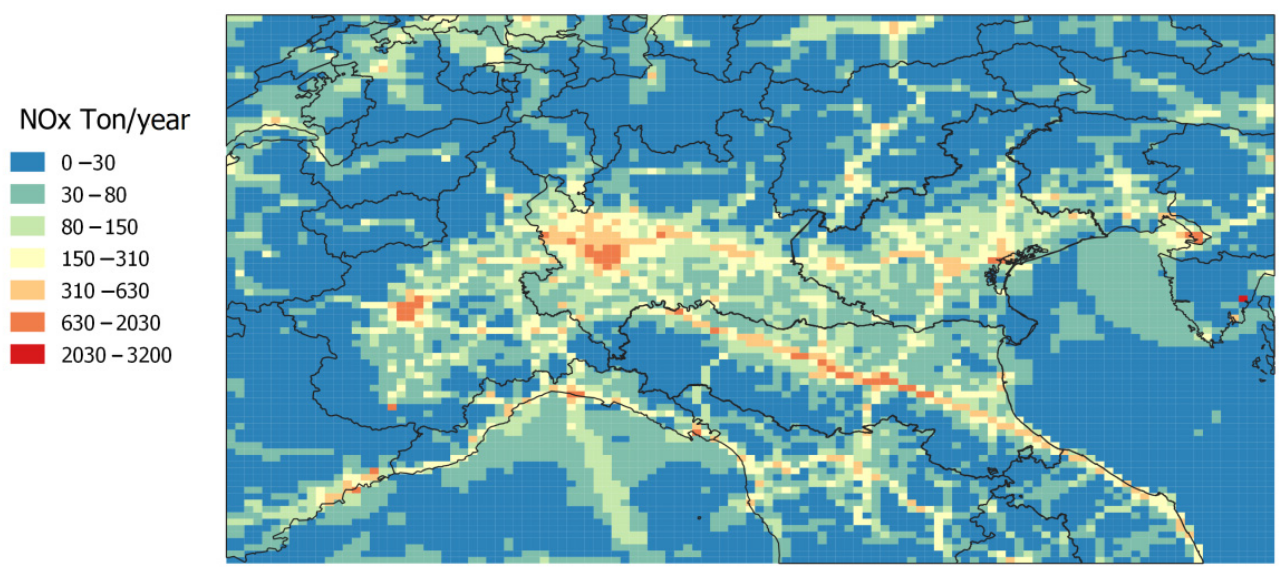

(a)

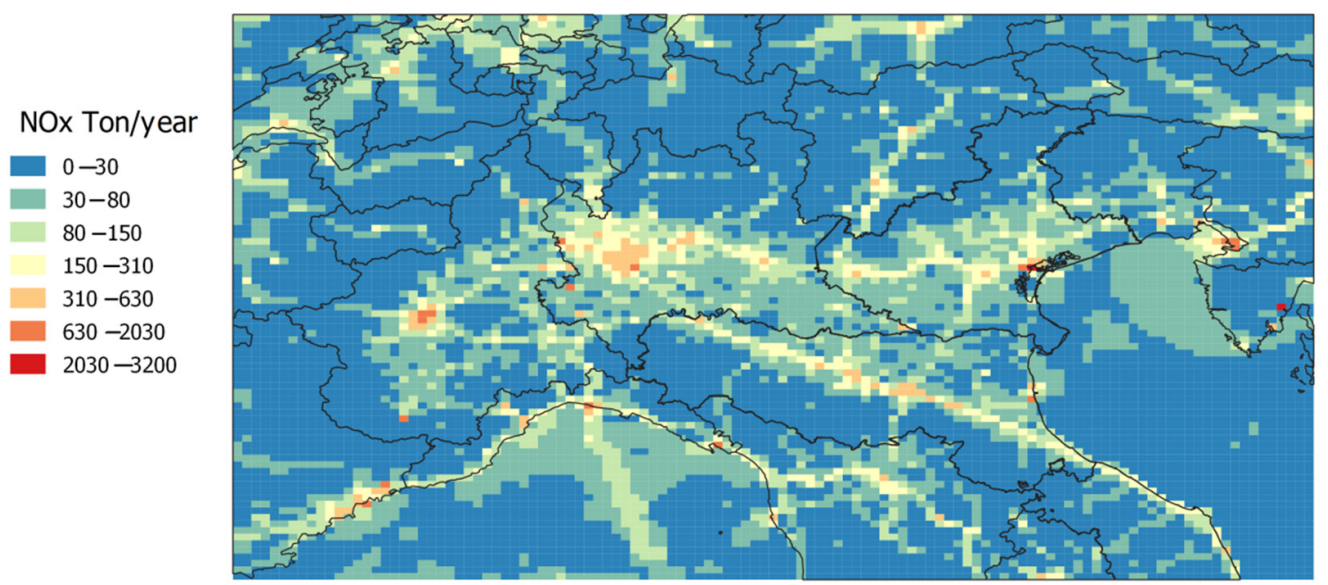

(b)

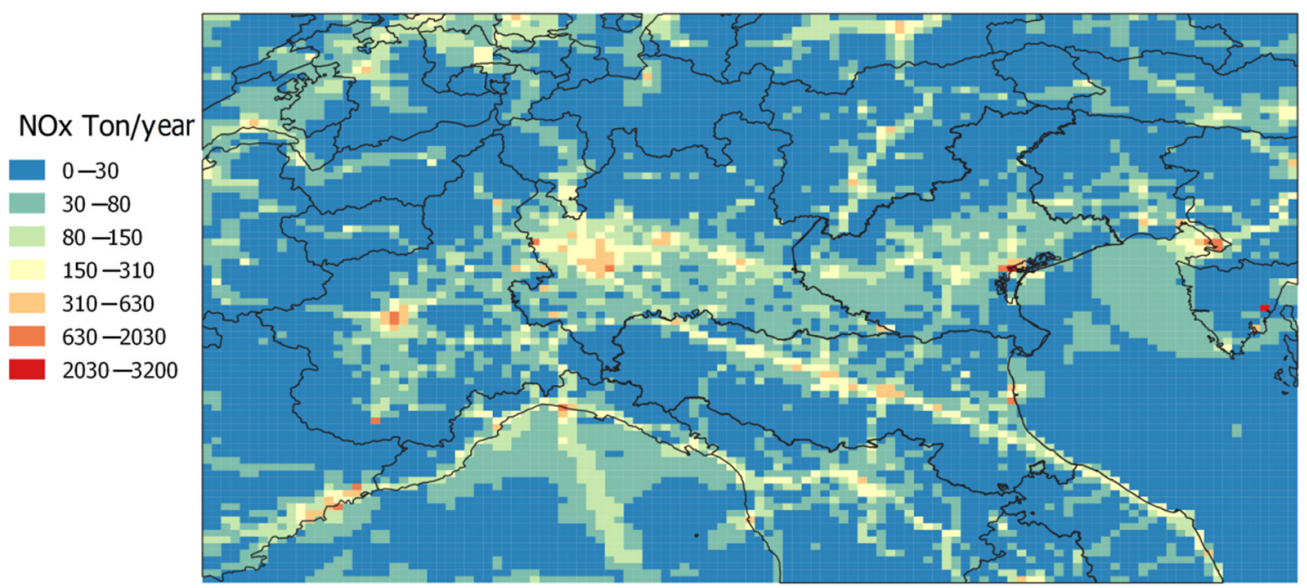

(c)

Figure 6. NOx emissions (Ton/year) for three simulated scenarios: (a) baseline; (b) CLE2025; and (c) APS2025. 
The purpose of these three scenarios is to evaluate the effectiveness of the emission reduction measures to achieve compliance with the Air Quality Directive limit values for $\mathrm{PM}_{10}$ and $\mathrm{NO}_{2}$ [1]. The limit values considered are the annual average of $\mathrm{PM}_{10}$ (less than $40 \mu \mathrm{g} / \mathrm{m}^{3}$ ), the daily value of $\mathrm{PM}_{10}$, i.e., the average concentration of $24 \mathrm{~h}$ (no more than 35 days per year which exceed the $24 \mathrm{~h}$ average concentration of $50 \mu \mathrm{g} / \mathrm{m}^{3}$ ) and the annual average of $\mathrm{NO}_{2}$ (less than $40 \mu \mathrm{g} / \mathrm{m}^{3}$ ). These limit values are not achieved in most of the Po Valley.

\subsection{Baseline Simulation and Bias Removal Method}

The annual average model output for the baseline scenario simulation was compared first with the ground-level concentration for 2016 year, recorded by the network of air-quality monitoring stations. (Figure 7) which contains more than 140 stations belonging to the environmental agencies of the Italian regions and Slovenia, all partners to the project, and shared via the data-sharing platform set up by the PREPAIR C1 action.

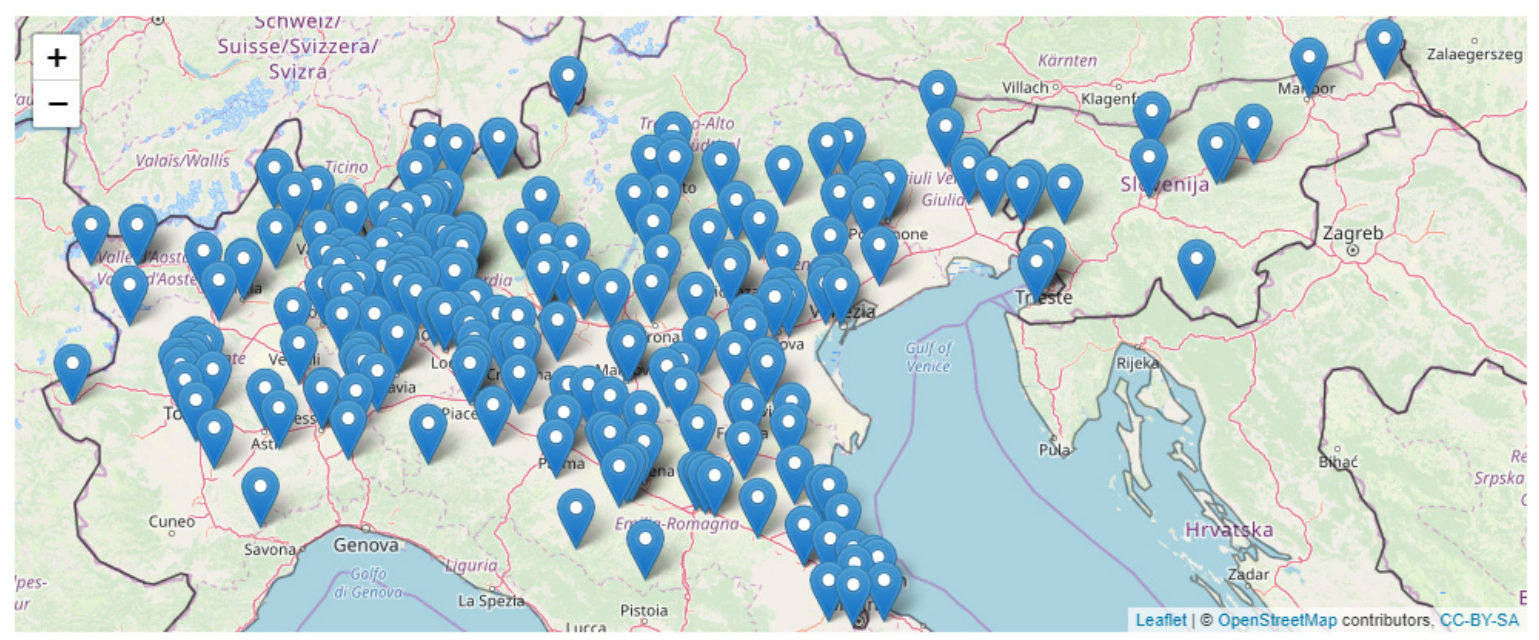

Figure 7. Station network for data sharing.

The first comparison highlighted a systematic bias for the $\mathrm{PM}_{10}$ and $\mathrm{NO}_{2}$ annual average concentration. Therefore, in order to remove the bias, a space-dependent correction using insitu observations data was applied. The correction field is obtained by using a spatialization of the adjustment factor:

$$
\mathrm{F}_{\mathrm{j}}=\mathrm{Obs}_{\mathrm{j}} / \mathrm{Mod}_{\mathrm{j}}
$$

where $\mathrm{Obs}_{\mathrm{j}}$ is the monitoring annual average, and $\mathrm{Mod}_{\mathrm{j}}$ is the model annual average at station $\mathrm{j}$.

The correction field was estimated by applying an ordinary kriging technique. The correction field is then used to adjust the output concentration of the NINFA model. In Table 3, skill scores with and without kriging correction are shown. Given the overall improvement in the quantitative scores, that results can be considered a good estimate of the "true" annual mean.

Table 3. Skill scores for $\mathrm{PM}_{10}$ and $\mathrm{NO}_{2}$ annual average with kriging and without kriging.

\begin{tabular}{ccccc}
\hline & \multicolumn{2}{c}{ PM $_{\mathbf{1 0}}$} & \multicolumn{2}{c}{ NO $_{\mathbf{2}}$} \\
\hline & No Kriging & With Kriging & No Kriging & With Kriging \\
\hline Bias $\left(\mu \mathrm{g} / \mathrm{m}^{3}\right)$ & -6.34 & 0.24 & -4.89 & 6.37 \\
\hline $\operatorname{RMSE}\left(\mu \mathrm{g} / \mathrm{m}^{3}\right)$ & 7.73 & 3.73 & 7.80 & 7.70 \\
\hline $\operatorname{MAE}\left(\mu \mathrm{g} / \mathrm{m}^{3}\right)$ & 6.72 & 2.78 & 6.37 & 5.69 \\
\hline
\end{tabular}


In order to estimate the compliance with the daily limit value (LV), a statistic relationship between the numbers of days and annual average concentration was used. Following this approach, an equivalent limit value (ELV) can be defined. Following the literature [15,16], an ELV equal to $28 \mu \mathrm{g} / \mathrm{m}^{3}$ can be applied.

The following figures show the ground field (left) and the frequency distribution for the background station (right) of the $\mathrm{PM}_{10}$ (Figure 8) and $\mathrm{NO}_{2}$ (Figure 9) annual average calculated by the unbiased model. In the baseline scenario, the $\mathrm{PM}_{10}$ annual average is lower than the $\mathrm{LV}$ of $40 \mu \mathrm{g} / \mathrm{m}^{3}$, but most stations exceed the ELV of $28 \mu \mathrm{g} / \mathrm{m}^{3}$. That means that the daily LV for $\mathrm{PM}_{10}$ is not attained. About ten stations exceed the $\mathrm{LV}$ for $\mathrm{NO}_{2}$ (Figure 9).

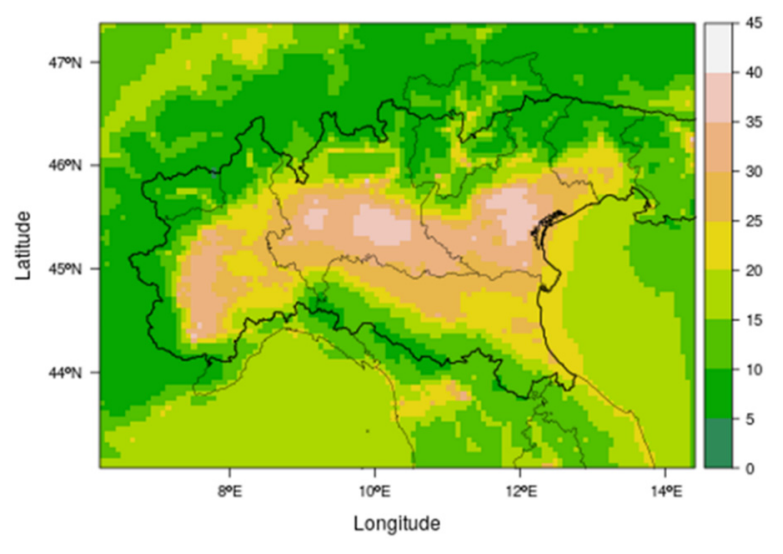

(a)

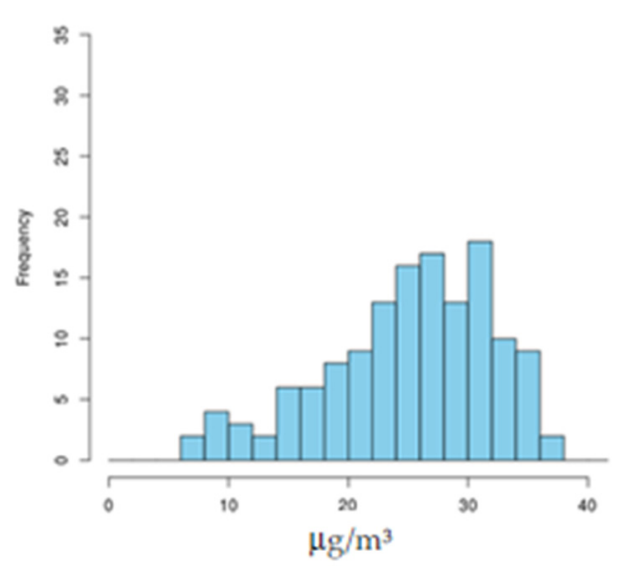

(b)

Figure 8. Baseline $\mathrm{PM}_{10}$ : (a) ground field of annual average concentration $\left(\mu \mathrm{g} / \mathrm{m}^{3}\right)$; (b) frequency distribution of annual average concentration in background stations.

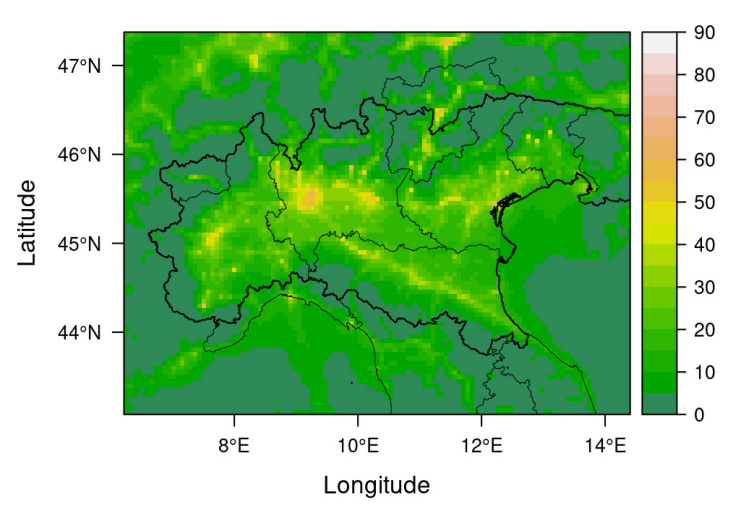

(a)

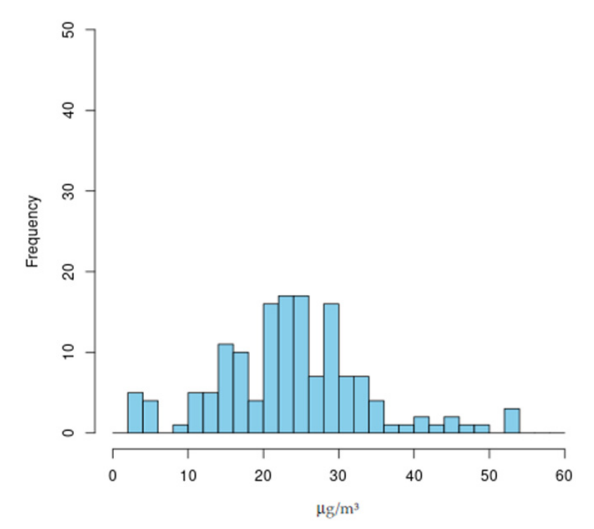

(b)

Figure 9. Baseline $\mathrm{NO}_{2}$ : (a) ground field of annual average concentration $\left(\mu \mathrm{g} / \mathrm{m}^{3}\right)$; (b) frequency distribution of annual average concentration in background stations.

\subsection{Emissions Scenarios Simulation}

In the current legislation emissions scenario (CLE2025), the decrease of $\mathrm{PM}_{10}$ annual average is evident in the central area of the Po Valley-the area of the big Milan urban agglomeration-and in correspondence with the main traffic arteries, although the annual values for $\mathrm{PM}_{10}$ concentration are higher than the ELV also in several background stations. The average reduction of the ground level concentration of $\mathrm{PM}_{10}$ is around $10 \%$ (Figure 10) with respect to the baseline. For $\mathrm{NO}_{2}$, the annual average concentration is lower than AQD LV in the background stations, with an average reduction of about $20 \%$ (Figure 11). 


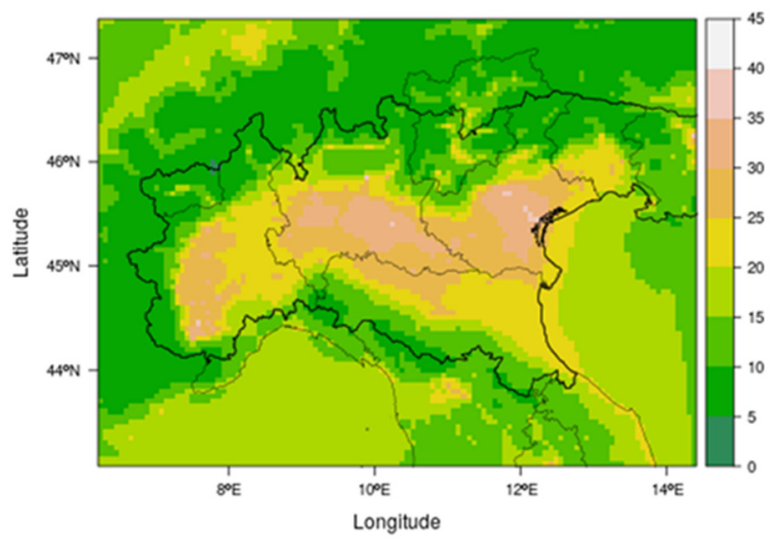

(a)

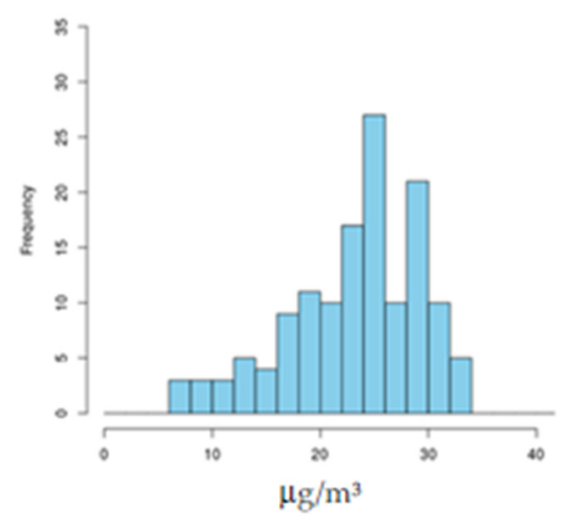

(b)

Figure 10. CLE2025 $\mathrm{PM}_{10}$ : (a) ground field of annual average concentration $\left(\mu \mathrm{g} / \mathrm{m}^{3}\right)$; (b) frequency distribution of annual average concentration in background stations.

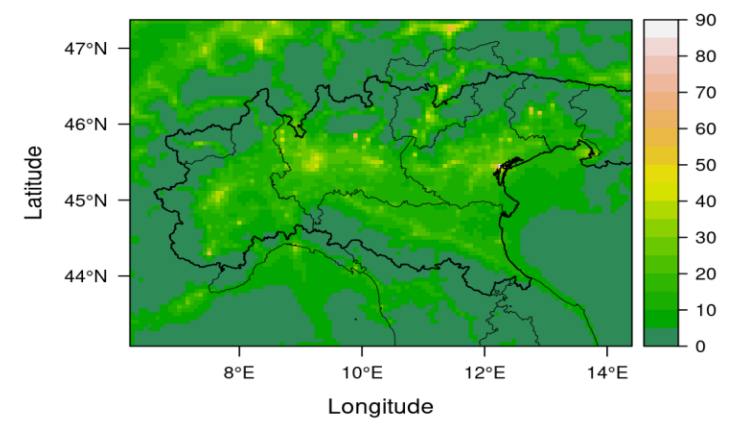

(a)

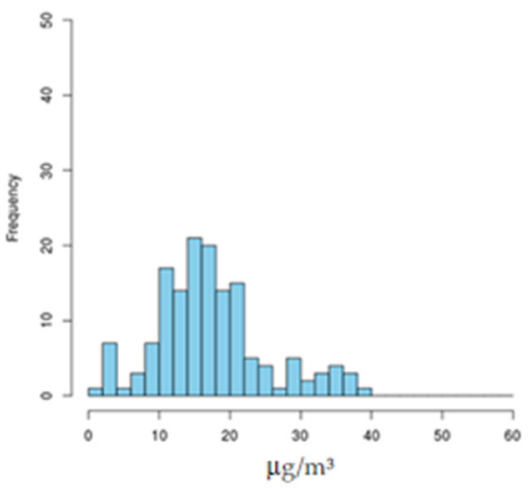

(b)

Figure 11. CLE2025 $\mathrm{NO}_{2}$ : (a) ground field of annual average concentration $\left(\mu \mathrm{g} / \mathrm{m}^{3}\right)$; (b) frequency distribution of annual average concentration in background stations.

The above results indicate that, for $\mathrm{PM}_{10}$, the compliance with AQD directive cannot be achieved by the year 2025. Therefore, as far as the CLE2025 emission scenarios are concerned, further emission-reduction actions are needed to reach the compliance.

The results for the model simulation of the action-plans emissions scenario (APS2025) are shown in Figure 12 for $\mathrm{PM}_{10}$ and in Figure 13 for $\mathrm{NO}_{2}$.

The exceedances areas $\left(\mathrm{PM}_{10}>28 \mu \mathrm{g} / \mathrm{m}^{3}\right)$ are strongly reduced in this scenario, and only one background station has a $\mathrm{PM}_{10}$ annual average concentration greater than the ELV. The average reduction of the ground-level concentration of $\mathrm{PM}_{10}$, compared to the baseline case, is around $20 \%$.

All background stations respect AQD LV for $\mathrm{NO}_{2}$ and the average reduction compared to baseline case is about $35 \%$.

The above results indicate that the compliance with AQD directive could be achieved in year 2025 by the full implementation of the sum of all the emissions reduction measures prescribed by the current legislation, the air-quality plans and Po valley agreements, i.e., in the APS2025 scenario. In this scenario, the overall emissions reductions of the main pollutants, compared with the emissions levels in the baseline, range between $20 \%\left(\mathrm{NH}_{3}\right)$ and $40 \%\left(\mathrm{PM}_{10}\right.$ and $\left.\mathrm{NOx}\right)$. To reach such a strong decrease in emissions, a deep transformation of the economy of the region and of the lifestyle of its population should take place. Low emissions technologies should be introduced in all sectors, with considerable economic and social impacts. 
The next question we address is as follows: Which is the role of the geographical characteristics and climatological conditions of the Po Valley? Due to those features, does the task of the complying to the European limits values in the Po Valley bear an element of disparity when compared to other regions of Europe and, therefore, to other member states? In the following section, a numerical experiment attempting to answer these questions is shown.

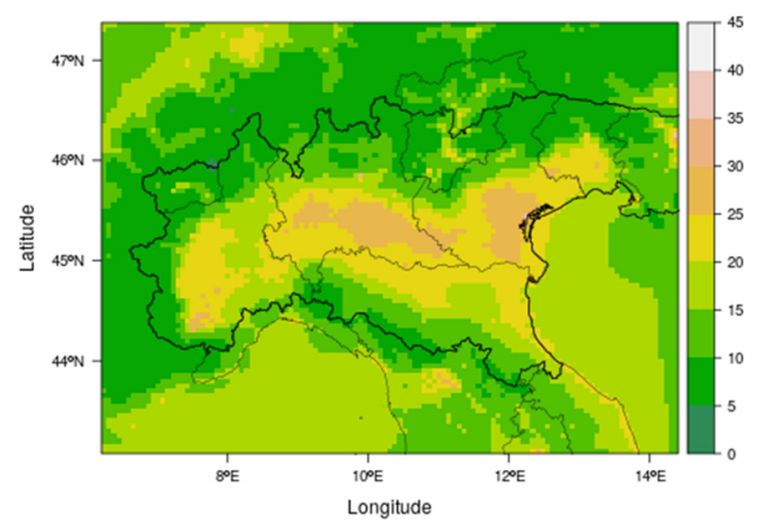

(a)

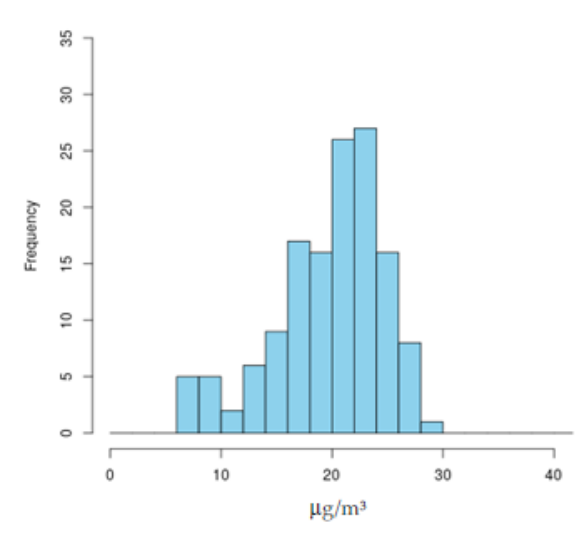

(b)

Figure 12. APS2025 $\mathrm{PM}_{10}$ : (a) ground level field $\left(\mu \mathrm{g} / \mathrm{m}^{3}\right)$; (b) frequency distribution of annual average concentration in background stations.

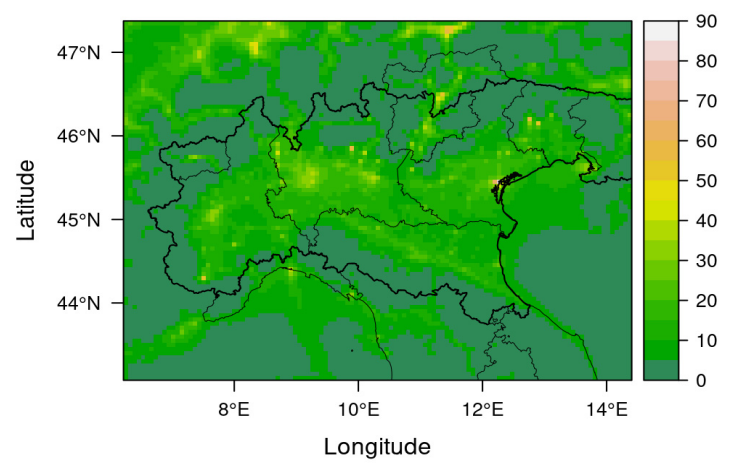

(a)

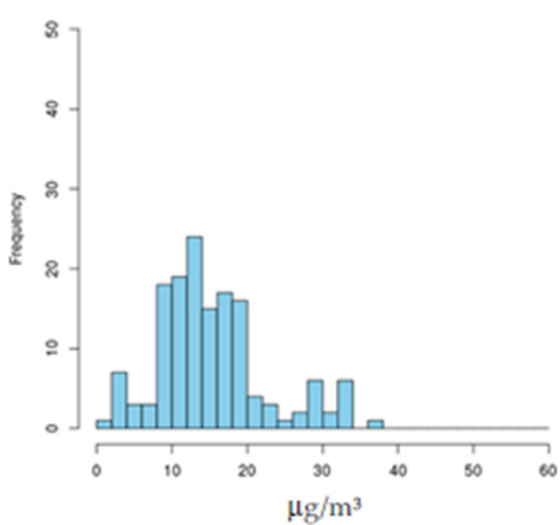

(b)

Figure 13. APS2025 $\mathrm{NO}_{2}$ : (a) ground field of annual average concentration $\left(\mu \mathrm{g} / \mathrm{m}^{3}\right)$; (b) frequency distribution of annual average concentration in background stations.

\section{Meteorological Scenario}

The topographical characteristics of the Po Valley strongly influence the local meteorology, leading to the typical climate of the region $[17,18]$ characterized by low winds, particularly weak in the winter months, with average speeds that are among the lowest in comparison to the rest of the European continent. In the Po Valley, due to the average weakness of the wind speed, the most important contribution to vertical mixing in the PBL (Planetary Boundary Layer) comes from the thermal component (vertical overturning due to buoyancy, mostly in summer and intermediate seasons). On the contrary, during wintertime, there are frequent thermal inversion conditions near the ground, particularly at night. This creates a single layer of diffuse and uniform pollution in the lowermost portion of atmosphere. Under these conditions, which can sometimes persist throughout the day, the dispersion of pollutants is severely hampered, with the primary pollutants tending to progressively accumulate near the ground, reaching high concentrations, and therefore favoring the formation of further secondary pollution. During these episodes, pollution is no longer limited to urban and 
industrial areas, but homogeneous high concentrations are recorded throughout the basin, including in rural areas, far from the emission sources. These explains why in the Po Valley the concentrations of most pollutants show a marked seasonal cycle, with winter values much higher than summer values, which in turn explains why almost all exceedances of LV occur in winter.

To check the sensitivity of the simulated monthly mean aerosol and gas concentration $\left(\mathrm{PM}_{10}\right.$ and $\left.\mathrm{NO}_{2}\right)$ in the Po valley upon the meteorology of the region (i.e., to highlight how a calm meteorological condition can impact on the pollutants concentration), we performed an adhoc experiment. The aim of the experiment is to investigate the change in concentrations, with the same emission levels, under different and "realistic" meteorological conditions.

This consisted of simulating pollutant concentrations over the Po Valley, in the presence of meteorological conditions more favorable to the dispersion of pollutants, at least compared to those which occur in situations typical of winter months. This investigation was therefore an attempt to provide a quantitative evaluation of how the peculiar mesoscale atmospheric circulation of the Po Valley, linked to low-level frequent stagnant conditions, influences the pollutant concentrations during winter months. We first identified a geographical area in which reasonably favorable dispersion conditions occurred during December 2018, and then we used the atmospheric variables estimated in this area (i.e., the upper box of Figure 14) as meteorological input for the experimental run. We selected an area of Central Europe in which the 10m wind speed averaged over December 2018, as estimated through daily analyses of the COSMO-5M model, showed considerably higher values than in the Po Valley. As a caveat, it is worth pointing out that this operation is internally consistent only if we consider Northern Italy substantially as a flat region

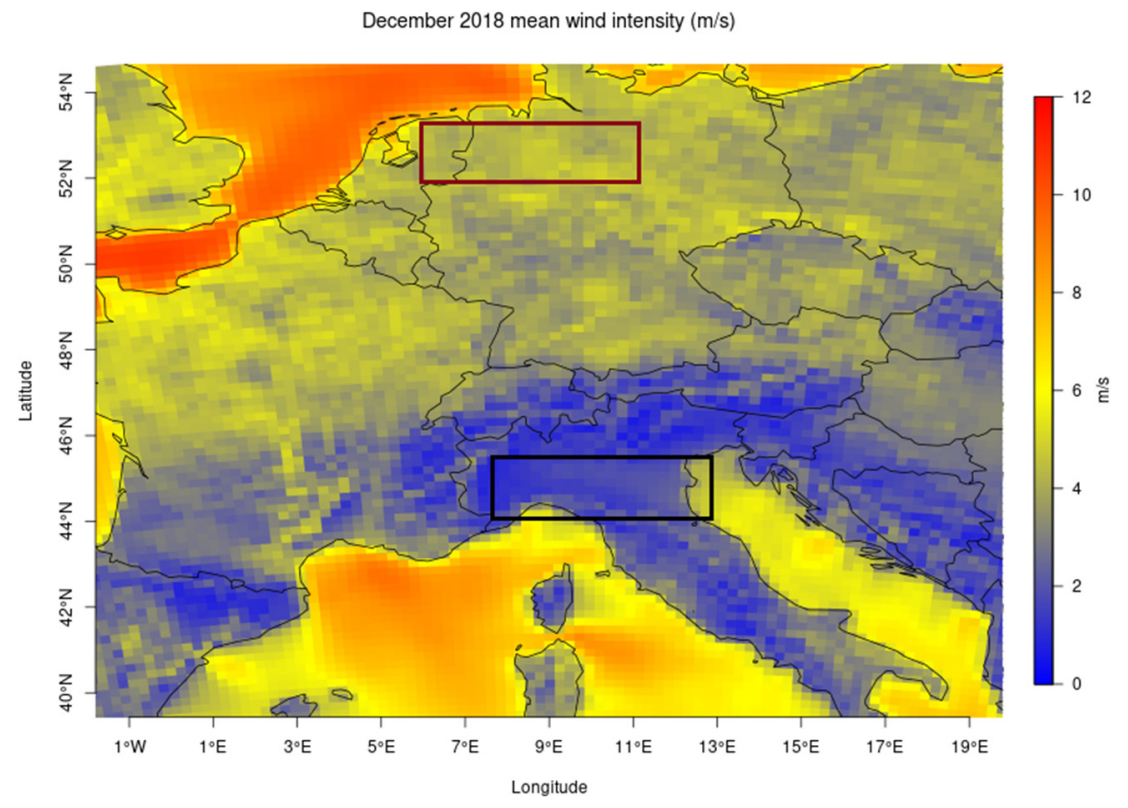

Figure 14. December 2018 average wind speed. The two areas (boxes) selected for the experiment are the Po Valley flat area and Northern-Central Europe area.

The experiment then consisted of running two examples of the NINFA system in hindcast mode simulating the air quality for a one-month period with an integration domain which falls inside the Po basin (lowermost blue box, Figure 14). In both cases, the anthropogenic emissions were taken from baseline scenario. The first run uses the standard Po Valley meteorology during December 2018, while in the second, the meteorology is substituted with the meteorology present in Northern-Central Europe (uppermost box of Figure 14) in the same period (Meteotest Scenario).

The ground level pollutants concentration obtained through the two simulations are then compared in terms of monthly averaged values, instead of day-by-day values. The monthly average is chosen to filter out the day-to-day high-frequency variability of the meteorological systems acting at the synoptic 
scale. The main results obtained are presented in the next two figures, in which the decrease of the monthly average concentration of $\mathrm{PM}_{10}$ and $\mathrm{NO}_{2}$ for the two integrations is compared.

The maps clearly show an overall reduction in the Meteotest Scenario, with respect to the baseline scenario:

- For $\mathrm{PM}_{10}$ concentration, a decrease of about $60-70 \%$ in the plane areas. The maximum decrease, up to $70-80 \%$, is in the west part of the Po Valley.

- For $\mathrm{NO}_{2}$ concentration, the decrease in the Meteotest Scenario is about $60 \%$.

\section{Conclusions}

This work describes the air-quality monitoring and evaluation system implemented in the first phase of the project LIFE-IP PREPAIR. It also illustrates the results of a first application of the system aimed at evaluating the level of air pollutants expected in the Po Valley in the year 2025 as it might result from the possible implementation of several emission reduction scenarios. The results of these assessments are used to support air-quality improvement policies by the regional administrations, which are partners of the project.

The PREPAIR air-quality monitoring and evaluation system allows us to collect and share, among the project partners, data and information necessary to evaluate the effectiveness of air-quality plans and to monitor the state of implementation of the measures. The system is composed of a platform for collecting and sharing data on emissions, a web-tool for monitoring the state of implementation of the measures of the air-quality plans and by a platform for sharing the data registered by the monitoring stations. These data are used as input to a chemical transport model (NINFA) bias-corrected with the observed data. The model is integrated to evaluate the air quality in the Po Valley and in Slovenia.

The emissions inventory referring to the current situation (baseline scenario) identifies the main contributions to the emissions of particulate matter (PM) and precursors. Primary $\mathrm{PM}_{10}$ emissions are mainly due to the macro-sector of non-industrial combustion (Table 2), with a strong contribution from domestic biomass combustion. The second major contribution comes from road transport, which, together with combustion in productive activities, represents the main contribution to $\mathrm{NO}_{\mathrm{X}}$ emissions. Ammonia, an important precursor, together with VOCs and NOx, of secondary PM, is emitted almost entirely from agriculture. Volatile organic compounds (VOCs) are mainly emitted using solvents. The evaluation of the baseline scenario by the NINFA model, in typical meteorological conditions of the Po Valley (year 2016), confirms the presence of large exceedance areas of the annual and daily limit values for $\mathrm{PM}_{10}$ (Figure 8 ) and the occurrence of a considerable number of stations recording values higher than the Limit Value for $\mathrm{NO}_{2}$ (Figure 9).

In the emission scenario that considers the emissions reduction due to enforcement in 2025 of the current legislation applied to the current baseline scenario, (CLE2025), the limit values for $\mathrm{PM}_{10}$ are not reached (Figures 10 and 11). Consequently, in order to reach LVs, more measures must be applied to contain emissions. These measures are introduced in Italy by a series of regional plans and national agreements. A further element is represented by the capacity building measures contained in the PREPAIR project. It is estimated that these measures would lead to an overall emissions reduction ranging between $20 \%\left(\mathrm{NH}_{3}\right)$ and $40 \%\left(\mathrm{PM}_{10}\right.$ and NOx). These reductions were used to build the further emission scenario (APS2025). The evaluation of the air quality in this scenario leads to the conclusion that, in the typical meteorological conditions of the Po Valley, the annual and daily limit values for $\mathrm{PM}_{10}$ would be attained (Figure 12). The annual limit value for $\mathrm{NO}_{2}$ would be attained in all the background stations (Figure 13).

A further numerical simulation based upon the same baseline scenario, with alternative meteorological conditions typical of Central-Northern Europe, shows that, with the same emission levels, the $\mathrm{PM}_{10}$ concentrations in the central Po Valley would be lowered to about $60 \%$, (Figure 15). This shows, convincingly, the disadvantages always faced by the Italian Po Valley regions in trying to comply with LVs, compared to other regions and member states of the EU. 


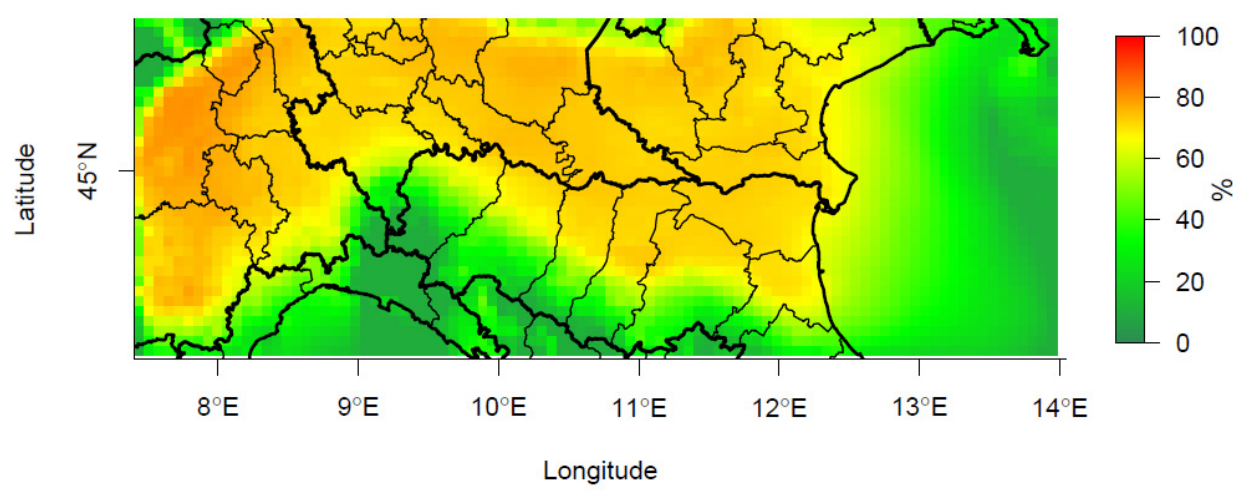

(a) PM10

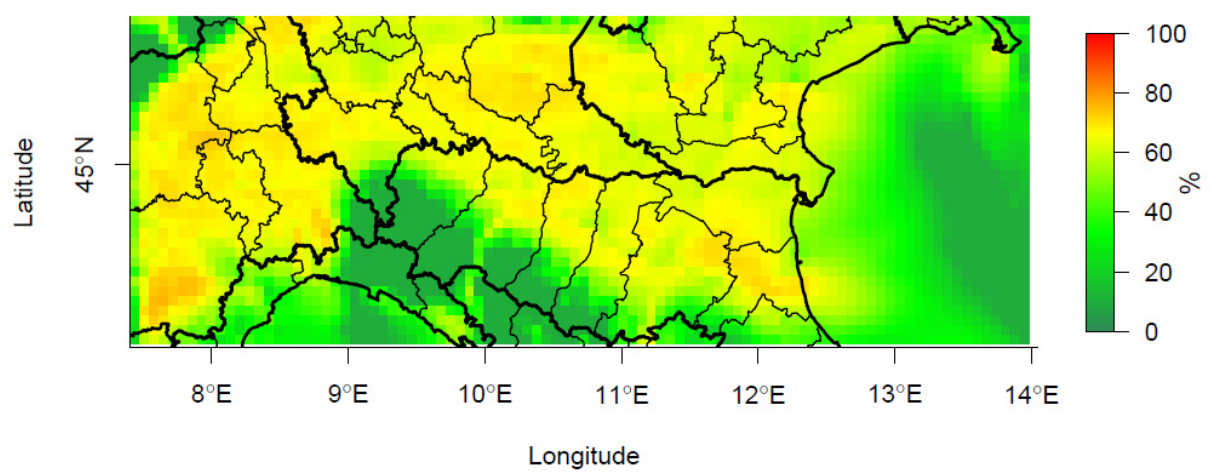

(b) $\mathrm{NO}_{2}$

Figure 15. December 2018 (a) $\mathrm{PM}_{10}$ reduction and (b) $\mathrm{NO}_{2}$ reduction.

As said before, one of the goals of the PREPAIR project is to assist the administrations in implementing the air-quality plans, in order to comply with the European air-quality standards. The indications for policy makers that arise from this preliminary assessment can be summarized as follows:

- A strong role in reducing emissions is played by European policies, but a rigorous application of all further measures envisaged by regional plans and national agreements is necessary. The European legislation measures that make up the CLE2025 scenario act mainly on the transport sectors, through the introduction of new approval limits for vehicles and the progressive replacement of internal combustion technology with electric technology.

- The measures of the regional air-quality plans mainly act on the sectors of regional competence, such as agriculture, which produces ammonia $\left(\mathrm{NH}_{3}\right)$. The reductions of ammonia are due solely to the measures implemented by the regional Rural Development Programmes (RDP). Other relevant sectors on which to act are the containment of emissions due to the domestic combustion of biomass and mobility management measures.

The rigorous application of these measures has a strong socioeconomic impact. It is therefore necessary to accompany these measures with initiatives aimed at improving the speed of their application and their social acceptability. The LIFE-IP PREPAIR project plays an important role in helping a quicker diffusion of advanced technologies and in changing individual behavior in order to accelerate the implementation of the AQ plans. Capacity building actions must be further strengthened by incentives and by research into use and development of low-emission technologies.

To achieve the goals of the air-quality improving policies, it is therefore indispensable that European, national, regional and local levels shall cooperate closely. 


\section{Post Scriptum}

During the COVID-19 pandemic, the relationships between air pollution and health are becoming more and more significant, showing once again the importance of actions aimed at improving air quality [19].

As far as the project PREPAIR is concerned, due to the so-called lockdown measures adopted in Italy and over the world to contain the pandemic, some data will not be available in the period. On the other side, the lockdown allows to get data on scenarios so far only hypothesized (such as the reduction of traffic on the roads and the reduction of the industrial consumptions) in order to improve monitoring and evaluation modelling. Therefore, it has been decided inside the project itself to realize an analysis for the assessment of air quality in the Po Valley and in Slovenia during the period of application of the COVID-19 measures (COVID lock down). The outcomes of this analysis will be available for epidemiological studies related to the effects of air pollution on health, also with reference to the COVID-19 pandemic.

Author Contributions: Data curation, M.S.; funding acquisition, K.R.; methodology, M.S., R.A. and M.V.; project administration, K.R. and M.D.; software, M.S., R.A., M.V. and G.G.; supervision, K.R. and M.D.; validation, G.G. R.A.; writing—original draft, K.R.; writing—review and editing, M.D., M.S., R.A. and M.V. All authors have read and agreed the published version of the manuscript.

Funding: This study was developed under the project LIFE-IP PREPAIR (Po Regions Engaged to Policies of AIR), which was co-funded by the European Union LIFE Program, in 2016, Grant Number LIFE15 IPE/IT/000013.

Acknowledgments: Acknowledgments are given to all the Beneficiaries of the project LIFE-IP PREPAIR: Emilia-Romagna Region (Project Coordinator) Veneto Region, Lombardy Region, Piedmont Region, Friuli Venezia Giulia Region, Autonomous Province of Trento, Regional Agency for Environment of Emilia-Romagna (ARPAE), Regional Agency for Environment of Veneto, Regional Agency for Environment of Piedmont, Regional Agency for Environmental Protection of Lombardy, Environmental Protection Agency of Valle d'Aosta, Environmental Protection Agency of Friuli Venezia Giulia, Slovenian Environment Agency, Municipality of Bologna, Municipality of Milan, City of Turin, ART-ER, Lombardy Foundation for Environment. We are grateful to Stefano Tibaldi for several useful comments about this work.

Conflicts of Interest: The authors declare no conflict of interest.

\section{References}

1. AQD. Directive 2008/50/EC of the European Parliament and of the Council of 21 May 5222008 on Ambient Air Quality and Cleaner Air for Europe. Off. J. 2008, 152, 1-44. Available online: http://eur-lex.europa.eu/ LexUriServ/LexUriServ.do?uri=OJ:L:2008:152:0001:0044:EN:PDF (accessed on 8 July 2012).

2. Monterio, A.; Durka, P.; Flandorfer, C.; Georgieva, E.; Guerreiro, C.; Kushta, J.; Malherbe, L.; Maiheu, B.; Miranda, A.I.; Santos, G.; et al. Strengths and weaknesses of the FAIRMODE benchmarking. Air Qual. Atmos. Health 2018, 11, 373-383. [CrossRef]

3. Viaene, P.; Janssen, S.; Thunis, P.; Trimpeneers, E.; Wesseling, J.; Montero, A.; Miranda, A.; Stocker, J.; Olesen, H.R.; Guerreiro, C.; et al. Guidance Document on Model Quality Objectives and Benchmarking. 2015. Available online: https://fairmode.jrc.ec.europa.eu/document/fairmode/WG1/Guidance_MQO_Bench_vs1.0. pdf (accessed on 10 March 2017).

4. LIFE PREPAIR Presentation of the Project. Available online: http://www.lifeprepair.eu/wp-content/uploads/ 2018/02/PREPAIR_introduction-to-the-project.pdf (accessed on 10 December 2019).

5. Marongiu, A.; Angelino, E.; Fossati, G.; Moretti, M.; Pantaleo, A.; Peroni, E. LIFE IP PREPAIR ACTION A.1 Emissions Data Set-Final Report. 2019. Available online: http://www.lifeprepair.eu/wp-content/uploads/ 2017/06/Emissions-dataset_final-report.pdf (accessed on 4 January 2020).

6. INEMAR Official Site. Available online: http://www.inemar (accessed on 10 December 2019).

7. EMEP/EEA Air Pollutant Emission Inventory Guidebook. 2019. Available online: https://www.eea.europa (accessed on 10 December 2019).

8. GAINS Italy Online-Air Quality and Greenhouse Gases-IIASAgains.iiasa.ac.at Gains. Available online: https://gains.iiasa.ac.at/gains/IT/index.login?logout=1 (accessed on 10 January 2020). 
9. Stortini, M.; Amorati, R.; Deserti, M.; Ramponi, L.; Carbonara, C.; Raffaelli, K.; Pillon, S.; Bonafè, G.; Petrini, A.; Clemente, M.; et al. LIFE IP PREPAIR ACTION A3 Preliminary Assessment of the Air Quality Plans-Final Report. 2019. Available online: http://www.lifeprepair.eu/wp-content/uploads/2017/06/PRELIMINARYASSESSMENT-OF-THE-AIR-QUALITY-PLANS.pdf (accessed on 10 January 2020).

10. Mailler, S.; Menut, L.; Khvorostyanov, D.; Valari, M.; Couvidat, F.; Siour, G.; Turquety, S.; Briant, R.; Tuccella, P.; Bessagnet, B.; et al. CHIMERE-2017: From urban to hemispheric chemistry-transport modeling. Geosci. Model Dev. 2017, 10, 2397-2423. [CrossRef]

11. Doms, G.; Baldauf, M. A Description of the Non Hydrostatic Regional COSMO-Model. Part I: Dynamics and Numeric. User Guide Documentation. 2018. Available online: www.cosmo-model.org (accessed on 10 January 2020).

12. Steppeler, J.; Doms, G.; Schättler, U.; Bitzer, H.W.; Gassmann, A.; Damrath, U.; Gregoric, G. Meso-gamma scale forecasts using the non-hydrostatic model LM. Meteorol. Atmos. Phys. 2003, 82, 75-96. [CrossRef]

13. Bienvenue sur PREVAIR. Available online: http://www2.prevair (accessed on 15 December 2019).

14. Stortini, M.; Arvani, B.; Deserti, M. Operational Forecast and Daily Assessment of the Air Quality in Italy: A Copernicus-CAMS Downstream Service. Atmosphere 2020. "Special Issue Recent Advances of Air Pollution Studies in Italy" (under review).

15. Deserti, M.; Stortini, M.; Minguzzi, E.; Maccaferrri, S. RIAT+, an integrated assessment tool useful for air quality planning: An application to Emilia Romagna region. Int. J. Environ. Pollut. 2019, 65, 59-70. [CrossRef]

16. Stedman, J.R.; Kent, A.J.; Grice, S.; Bush, T.J.; Derwent, R.G. A consistent method for modeling PM10 and PM2.5 concentrations across the United Kingdom in 2004 for air quality assessment. Atmos. Environ. 2007, 41, 161-172. [CrossRef]

17. Finardi, S.; Pellegrini, U. Systematic analysis of meteorological conditions causing severe urban air pollution episodes in the central Po Valley. In Proceedings of the 9th International Conference on Harmonisation within Atmospheric Dispersion Modelling for Regulatory Purposes, Garmish-Partenkirchen, Germany, 1-4 June 2004; pp. 250-254.

18. Pernigotti, D.; Georgieva, E.; Thunis, P.; Bessagnet, B. Impact of meteorological modelling on air quality: Summer and winter episodes in the Po valley (Northern Italy). Int. J. Envir. Poll. 2014, 50, 111-119. [CrossRef]

19. Wu, X.; Nethery, R.C.; Sabath, M.B.; Braun, D.; Dominici, F. Exposure to Air Pollution and COVID-19 Mortality in the United States; Harvard T.H. Chan School of Public Heath: Boston, MA, USA, 2020. [CrossRef] 